\title{
How to Manage the Build-up of Light-ends in Heat Transfer Fluids: A Practical Guide to Interventions to Safely Mitigate and Correct their Accumulation
}

\section{Chris Wright*}

Global Heat Transfer, Cold Meece Estate, Cold Meece, Stone, Staffordshire, UK

\begin{abstract}
'Light-ends' are a volatile and flammable by-product that, with sustained operation at high temperature, work to reduce the flash temperature of the heat transfer (HTF). Manufacturers have a duty to manage their build-up according to current safety regulations (e.g. the dangerous substances and explosive atmospheres regulations 2002). The current article discusses the process by which light-ends are formed in a HTF, how they are detected and current approaches to their management.

A heat transfer fluid (HTF) is a heat carrier that is pumped through a closed system (HTF system) and used to heat an object. This process is used to achieve thermal stability and vital to the generation of homogenous end-products (e.g. from processed foods to the creation of plastic cartons). The composition of high temperature HTFs fails into one of three broad categories: organic HTFs (e.g. BP Transcal N, Shell Thermia B, Globatherm ${ }^{\circledR}$ M); highly refined organic HTFs (e.g. Marlotherm FG, Globatherm ${ }^{\circledast}$ FG); and, synthetic HTFs (e.g. Therminol 66, Dowtherm A, Therminol VP-1, Globatherm ${ }^{\circledast}$ Omnitech).
\end{abstract}

Keywords: Heat transfer fluid; Volatile; Temperature; Oxygen

\section{The Aging and Cracking of a HTF}

With extended use at high temperature a HTF will thermally degrade and eventually need to be replaced. Organic HTFs, for example, will react with oxygen and this will age the fluid and so its oxidation stability is crucial to sustaining its longevity [1,2]. It is also well known that in the presence of oxygen, its rate of aging will rapidly accelerate above a temperature of 60 degrees Celsius (140 degrees Fahrenheit) at which point every rise of 10 degrees Celsius will double the rate of ageing of the HTF according to Arrhenius's rule [3]. At the molecular level, oxygen has the ability to join the carbon atom in a hydrocarbon HTF and also push between the two hydrogen atoms (Figure 1). Hence, a fluid's environment and chemistry determines how well it resists molecular rearrangement or breakdown at elevated temperatures [4] and in turn this dictates its thermal stability and duration of use [2].

The addition of the oxygen molecule works to convert the saturated hydrocarbons (alkanes) into organic acids. If left to age organic acids will form in the HTF and polymerisation products will be produced and circulate in the HTF or precipitate out of the HTF if their have sufficient molecular weight. Oxidation will also lead to increased HTF viscosity.

Another factor at play in the aging process is the thermal cracking of an organic HTF, whereby prolonged use at high temperature (and pressure) leads to the breakdown of long-chain hydrocarbons into short-chain hydrocarbons (referred to as 'light hydrocarbons' or 'light

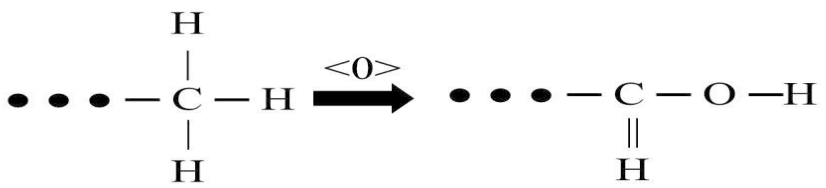

Figure 1: Oxygen and its influence on the molecular arrangement of a hydrocarbon fluid. ends' or 'light fuels') through the breaking of carbon-carbon bonds. As this process continues it leads to the formation of light-ends in the HTF and their accumulation leads to the progressive decline in the flash point temperature of the HTF.

In everyday practice these processes are reflected in the test reports and these can be quantified by an experienced supplier. Table 1 shows the test parameters that are routinely measured and how the data is used by the customer, in collaboration with the supplier, to assess the condition of the fluid. In Table 1 the composite results from 793 test reports are shown [5]. Results are from plants using an organic HTF. To the trained eye the effect of aging can be deduced from the increasing total acid number (TAN; is an indirect measure of oxidative state) and the increasing carbon residue value. The data also shows a progressive increase in viscosity with increased mean TAN and carbon residue values. However, carbon forms at a rate of 2:1 relative to TAN and so the carbon residue value also reflects a certain amount of thermal cracking, which is observed as increasing carbon and decreasing flash point values.

\section{Flash Point Temperature}

Flash point is defined as the temperature at liquid fuels develop vapours and if mixed with air these can potentially be an ignition source and thus present a fire risk to an operating plant. The safety data sheet supplied with a fluid will define the characteristics of a particular

*Corresponding author: Chris Wright, Global Heat Transfer, Cold Meece Estate, Cold Meece, Stone, Staffordshire, UK, Tel: 447967230155; E-mail: ciwright26@hotmail.com

Received August 03, 2018; Accepted September 22, 2018; Published Septembe 28, 2018

Citation: Wright C (2018) How to Manage the Build-up of Light-ends in Hea Transfer Fluids: A Practical Guide to Interventions to Safely Mitigate and Correct their Accumulation. Fluid Mech Open Acc 5: 185. doi: 10.4172/2476-2296.1000185

Copyright: $\odot 2018$ Wright $C$. This is an open-access article distributed under the terms of the Creative Commons Attribution License, which permits unrestricted use, distribution, and reproduction in any medium, provided the original author and source are credited. 
Citation: Wright C (2018) How to Manage the Build-up of Light-ends in Heat Transfer Fluids: A Practical Guide to Interventions to Safely Mitigate and Correct their Accumulation. Fluid Mech Open Acc 5: 185. doi: 10.4172/2476-2296.1000185

Page 2 of 3

HTF and this will include open and closed flash point temperatures. Table 2 shows the open and closed flash point temperatures for an organic, highly refined and synthetic fluid, and clearly highlights that the properties of these fluids are not the same.

Table 2 also shows that the closed flash point temperature is lower than the open flash point temperature. The reason for this is explained by the method used to test a fluid's flash point temperatures [5]. The open-cup method (referred to as the Cleveland open cup flash-point test and measured according to standard D92 defined by the American Society for Testing and Materials (ASTM). In this test the vapours are partly removed by unavoidable air movement. In contrast, the closed-cup method (the Pensky-Martens closed-cup flash-point test and measured according to ASTM D93) ensures that all vapours are kept together and effectively removes the influence of air movement as a factor in the test. The closed flash point temperature is effectively the lowest temperature where there is sufficient flammable vapour to ignite in the presence of an ignition source. ASTM D92 and D93 are commonly measured as part of a fluid management plan.

\section{How to Manage the Build-Up of Light-Ends in Heat Trans- fer Fluids}

The objective of any fluid management plan is to quantify the extent of flammable decomposition products in the HTF in order to understand the risk they present to the safety of the plant or to define interventions that will mitigate their risk.

\begin{tabular}{|l|c|c|c|c|c|}
\hline & \multicolumn{5}{|c|}{ Carbon residue, \% weight } \\
\hline Parameter & $<0.05$ & $\begin{array}{c}\geq 0.05 \text { to } \\
<0.5\end{array}$ & $\begin{array}{c}\geq 0.5 \text { to } \\
<0.75\end{array}$ & $\begin{array}{c}\geq .75 \\
<1.0\end{array}$ & $\geq 1.0$ \\
\hline $\begin{array}{l}\text { Number of samples chemically } \\
\text { analysed }\end{array}$ & 82.0 & 793.0 & 46.0 & 30.0 & 30.0 \\
\hline Water content, ppm & 90.4 & 84.5 & 83.6 & 63.0 & 182.9 \\
\hline Kinematic viscosity, $\mathrm{mm}^{2} / \mathrm{s}$ & 30.3 & 30.2 & 30.9 & 33.8 & 36.2 \\
\hline $\begin{array}{l}\text { Elements, e.g., silicon (ppm less } \\
\text { than 5 } \mu \mathrm{m})\end{array}$ & 11.8 & 14.3 & 18.3 & 11.5 & 16.0 \\
\hline Total acid number (TAN), $\mathrm{mg} \mathrm{KOH} / \mathrm{g}$ & 0.1 & 0.2 & 0.3 & 0.5 & 0.5 \\
\hline Ferrous debris, insoluble & 7.0 & 15.6 & 20.9 & 17.8 & 29.1 \\
\hline Open flash point temperature, ${ }^{\circ} \mathrm{C}$ & 212.0 & 203.1 & 197.3 & 202.8 & 204.2 \\
\hline Closed flash point temperature, ${ }^{\circ} \mathrm{C}$ & 165.5 & 155.6 & 150.4 & 164.6 & 160.5 \\
\hline Fire point temperature, ${ }^{\circ} \mathrm{C}$ & 244.1 & 243.9 & 236.6 & 240.0 & 240.2 \\
\hline
\end{tabular}

Table 1: The physicochemical properties of the mineral-based HTF for each carbon level.

\begin{tabular}{|c|c|c|}
\hline HTF & Parameter & ${ }^{\circ} \mathrm{C}\left({ }^{\circ} \mathrm{F}\right)$ \\
\hline \multirow{3}{*}{$\begin{array}{c}\text { Organic (e.g. } \\
\text { Globatherm }^{\circledast} \mathrm{M}^{\mathrm{a}} \text { ) }\end{array}$} & Maximum bulk fluid temperature & $345(653)$ \\
\hline & Open flash point temperature & $230(446)$ \\
\hline & Closed flash point temperature & $210(410)$ \\
\hline \multirow{3}{*}{$\begin{array}{c}\text { Highly refined } \\
\text { (Globaltherm }{ }^{\circledast} \mathrm{FG}^{\mathrm{a}} \text { ) }\end{array}$} & Maximum bulk fluid temperature & $326(619)$ \\
\hline & Open flash point temperature & $216(421)$ \\
\hline & Closed flash point temperature & $210(410)$ \\
\hline \multirow{3}{*}{$\begin{array}{c}\text { Synthetic (Globatherm } \\
\text { Syntec } \\
\text { Sy) }\end{array}$} & Maximum bulk fluid temperature & $320(608)$ \\
\hline & Open flash point temperature & $184(363)$ \\
\hline & Closed flash point temperature & $170(338)$ \\
\hline
\end{tabular}

Table 2: Typical flash point values for organic, highly refined organic and synthetic HTFs.

Notes: Tested using ASTM D92 and ASTM D93. Values vary by chemistry and composition, and buyers should consult reputable HTF manufacturers / suppliers on product specific information.

\section{How to sample and chemically analyse a fluid}

In a previous article [6] entitled, 'How to sample heat transfer fluids' I outlined how to gain a representative HTF sample, how frequently a fluid should be sampled and chemically analysed as well as what standardised tests are routinely used to assess the thermal decomposition of a HTF. For further information the reader should refer to this article to gain more insights into industry standards and best practices.

\section{How to determine if the flash points are in or out of specification}

Once the fluid has been chemically analysed the test report should cite the flash point temperatures. Ideally the supplier should highlight if the values are in or out of specification. The simplest way is to colour code the values with, for example, green representing a satisfactory value and red a serious value. At Global Health Transfer this approach is combined with predetermined values for each HTF. Table 3 shows the condition ratings used for an organic fluid and this should be the basis for defining if a corrective intervention is required or not [7].

\section{Interventions which may help to mitigate declines in flash point temperatures}

Interventions that slow thermal degradation are of value in slowing the decline in flash point temperature. Indeed, it is well know that a HTF will degrade fluid and that this process can be accelerated by external contaminants. Hence, removal of external contaminants using a fine filter would be one approach. Interventions that can help to mitigate the build-up of light-ends may include:

Sample the HTF as frequently as possible: Research has shown that fluid condition is better when the fluid is sampled and chemically analysed more frequently (the best results being reported when a HTF was sampled once every 3 months). So, sample the fluid as often as possible to prevent detrimental changes [8].

Lower the bulk temperature: As previously mentioned, Arrehenius's Law [3] states that the rate of thermal decomposition is halved for every 10 degrees Celsius drop in bulk temperature. So, decrease the bulk operating temperature in steps of 10 degrees Celsius.

Dilute the HTF with a virgin fluid: Adding a percentage (up to $50 \%$ of the total volume) of virgin HTF to an existing system works to remove degradation by-products. This avoids the need to completely replenish the system and reduces the associated costs in doing this.

Recharge the system with a new fluid: A new fluid will remove the HTF and the degradation by-products from the system. This is an expensive option but may be required if the fluid has been condemned (i.e. the percentage carbon residue value is $\geq 1.0 \%$ or the TAN value is $\geq 0.4 \mathrm{mg} \mathrm{KOH} / \mathrm{g}$ ) [5].

Recharge the system with a synthetic fluid. It is well known that synthetic-based HTFs maximise the ability of a plant to operate at higher temperatures due to their better thermal stability, higher heat

\begin{tabular}{|c|c|c|c|c|}
\hline \multirow{2}{*}{ Characteristic } & \multicolumn{3}{|c|}{ Condition rating for an organic-based HTFs } \\
\cline { 2 - 5 } & Satisfactory & Caution & Action & Serious \\
\hline $\begin{array}{c}\text { Open flash } \\
\text { temperature }\left({ }^{\circ} \mathrm{C}\right)\end{array}$ & \multicolumn{2}{|c|}{$\leq 221$ to $>160$} & $\leq 160$ to $>150$ & $\leq 150$ \\
\hline $\begin{array}{c}\text { Closed flash } \\
\text { temperature }\left({ }^{\circ} \mathrm{C}\right)\end{array}$ & $\leq 210$ to $>130$ & $\begin{array}{c}\leq 130 \text { to } \\
>110\end{array}$ & $\leq 110$ to $>85$ & $\leq 85$ \\
\hline
\end{tabular}

Table 3: Organic HTFs-the condition rating for open and closed flash pint temperatures. 
transfer efficiency and higher purity. So, if an organic HTF is being used and there are funds to fill the system with a synthetic fluid, then this may help to slow thermal degradation.

Think about incorporating a fine filter into the HTF system. A filter works remove contaminants and debris from the circulating HTF [9]. Their removal will avoid their potential catalytic effects which can shorten the life of a fluid.

\section{Interventions that may help to Correct Declines in Flash Point Temperatures}

Ennis [10] described the process of thermal degradation as "When a heat transfer fluid degrades, it forms a combination of 'lights' and 'heavies'. The lights are short chain molecules formed by thermal cracking and may also include hydrogen gas. These have the effect of reducing the flashpoint of the HTF as well as being boiled off from the liquid as a flammable vapour."

Light-chain hydrocarbons ('light-ends') can be removed through distillation using batch venting or by installing a portable or permanent light-ends removal kit (LERK) [7].

Batch venting (intermittent approach): This involves heating the expansion tank to raise the temperature of the circulating HTF. This effectively vaporises the light-ends from the HTF system and light-ends escape during the process and are collected in a condenser. The volume of HTF that is heated is controlled by opening the valves on the purge line and the HTF is allowed to flow into the expansion tank. A nitrogen lance is required to stop the negative effect of oxidation that occurs at high temperatures. Batch vents are continued until no further lightends are collected. This approach is not suitable for all systems and expert advice should be sought on suitability. This approach should also be conducted by suppliers with experience in this field [7].

LERK installation (intermittent or permanent approach): In contrast to batch venting, a LERK can be installed intermittently, if a portable unit is deployed, or permanently. In both cases it operates in situ with the HTF system (Figure 2). Its big advantage is that it continuously removes flammable light-end by-products through distillation of vapours and prevents their build-up. Recently a permanently installed LERK was still effective up to 5 years after it was first installed [11]. Indeed, flammable vapours were shown to remain constant and had a satisfactory condition rating over the entire period.

\section{Summary}

HTFs are used at very high temperatures (up to 400 degrees Celsius is the standard in concentrated solar power plants). With prolonged use these fluids will start to degrade and the by-products that form need to be actively managed to help maintain a safe operating environment and to simply extend the fluid's operating life. Indeed, few companies understand that regularly servicing a HTF and HTF systems can help sustain their longevity. Global Heat Transfer examines how the build-up of short-chain hydrocarbons, a by-product of HTF thermal degradation, can be managed.

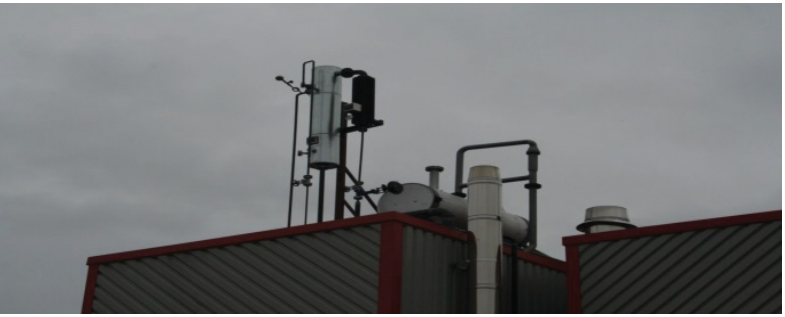

Figure 2: A picture of a permanently installed LERK. Picture curtesy of Global Heat Transfer.

Light-ends present a potential hazard that need to be managed to ensure the safe operation of a thermal system. A LERK can be extremely effective, offering the potential to prevent the build-up of light-ends by removing them during HTF thermal degradation. The current article highlights the approaches used to manage the build-up of light-ends, which can be offered as part of a well-designed maintenance plan, such as the Thermocare ${ }^{\circledR}$ programme offered by Global Heat Transfer Ltd, which can help to sustain the life of a HTF and a HTF system.

\section{Disclaimer}

This article is provided for guidance alone. Expert engineering advice should be sought before application.

\section{References}

1. http://www.hse.gov.uk/fireandexplosion/atex.htm

2. Wagner WO (1997) Heat transfer technique with organic media. Heat transfer media. [2 $2^{\text {nd }}$ edn] Graefelfing, Germany: Maria-Eich-Straße; pp: 4-58.

3. www.open.edu

4. Aluyor EO, Ori-jesu M (2009) Biodegradation of mineral oils-A review. African J Biotechnology 8: 915-920.

5. Wright $\mathrm{Cl}$ (2015) Comparing the thermal stability and oxidative state of mineral and biphenyl diphenyl oxide based heat transfer fluids. J Applied Mechanical Eng 4: 187.

6. Wright C (2017) How to sample heat transfer fluids. Risk \& Safety. The Chemical Engineer.

7. Wright $\mathrm{Cl}$, Premel J (2014) Heat transfer system safety: comparing the effectiveness of batch venting and a light-ends removal kit (LERK). Case Studies in Thermal Engineering 4: 215-221.

8. Wright $\mathrm{Cl}$, Picot E, Bembridge T (2015) The relationship between the condition of a mineral-based heat transfer fluid and the frequency that it is sampled and chemically analysed. Applied Thermal Engineering 75: 918-922.

9. Wright $\mathrm{Cl}$ (2016). The use of a flushing and cleaning protocol to remove foreign contaminants-a study from a newly built heat transfer plant with a capacity of 100 metric tonnes. Applied Thermal Engineering 101: 373-378.

10. Ennis $T$ (2009) Safety in design of thermal fluid heat transfer systems. Hazards XXI Symposium series number 155: 162-169.

11. Wright $\mathrm{Cl}$, Faure D, Bissemo $\mathrm{R}$ (2016) The long-term effectiveness of a lightends removal kit in the management of heat transfer fluid plant safety: a case study to show its effectiveness 5 years after installation. Heat Transfer Engineering. 